\title{
PREFACE TO THE PAPERBACK EDITION
}

IT IS PROBABLY A GOOD IDEA for every writer to review his or her work after a lapse of several years because time and distance permit a more dispassionate assessment of a thesis than when the author and the original manuscript were constant companions. Having just completed such a critique, I am able to report (with some sense of relief, I might add), that in the seven years since $A$ Dependent People was published, no newly discovered manuscript or recently issued book has created a need to modify its basic conclusions. At the same time, were I to explore the same subject today, I might give greater emphasis to topics which were only touched upon, and I might ask-and try to answer-questions that were not even raised seven years ago.

With the benefit of hindsight and further reading, I am not at all certain that I said enough about the prevailing attitude that influenced Newport's revolutionary expectations and actions. I am as convinced today as I was seven years ago that economic grievances precipitated Newport's entry into the war, yet today I would broaden that assertion to include a discussion of the intellectual baggage which made economic issues a raison d'être for rebellion. As $I$ argue in the book itself, self-interest was surely a motivating value, but how did this component fit into the total equation: Why would one person perceive that his self-interest was best served by "ideal" British duties and yet another see those same duties as a threat to his very survival? And what did survival mean in the context of eighteenth-century Newport? Was it simply having enough to eat, or was survival equivalent to upward mobility and prosperity? In short, what in their collective mentalite- what in the cumulative experience of this seaport town-made the hasty pursuit of profit more important than standing membership in the British empire?

It occurs to me now that the absence of a strong Puritan legacy might relate in some way to these questions. Strict Puritan doctrine demanded economic moderation and the suppression of self-interest for the good of the whole. But as tempting opportunities presented themselves, the history of seventeenth-century Massachusetts became, at least in part, a story of the conflict between expanding mercantilism and undiluted Puritanism. If it took almost a century for mercantile interests to prevail in Massachusetts, however, Rhode Island merchants achieved predominance in far less time. The original settlers of Newport found Boston's brand of Puritanism incompatible with their own as early as 1639 , and once they 
left their guilt on the Massachusetts side of the border, they had little reason to contain their accumulation of wealth. Revolutionary Newporters were merely heirs to a longstanding economic tradition in which a just price and low interest rates had little meaning even in theory.

A Puritan legacy in Massachusetts (and the near absence of one in Newport) may also explain the proliferation of pamphlet literature in Boston during the I 760 s and I770s, and the dearth of such position papers in Newport during the same period of time. Newporters never felt the necessity of justifying their actions in constitutional or ideological terms because they were never bound by an intellectual heritage that constrained their acquisitive instincts.

Pursuing this line of thought still further, I would speculate today-as I did not seven years ago-that the revolutionary confrontation between Congregationalists and Anglicans might be explained in the above context. The Anglicans were the furthest removed from Puritan economic guidelines while at the same time they were, as a group, the most affluent members of the Newport community. This combination of factors may have antagonized the Congregationalists whose resentment toward the economic achievements of their Anglican brethren was translated into rebellion. Does this interpretation make Newport's experience in the revolutionary era a class struggle? Not exactly, but perhaps it brings that argument out of total oblivion.

One other subject that deserves a more thorough analysis than I gave it in 1985 concerns personal relationships. If church affiliation was, as I believe it to have been, the key to revolutionary allegiances, how did this affect intra-family relationships? Were ordinary marital tensions heightened when husbands and wives supported opposing camps? What sort of strains were siblings subject to when they argued for-and even fought for-different sides? And how did parents treat a son or daughter whose revolutionary commitment differed from their own?

A final observation: if I am still comfortable with the basic argument of the book, I am less satisfied-indeed, I admit to wincing-at the sexist language that slipped by seven years ago. Please note, therefore, that I had men and women in mind in the last paragraph on page 2 , and on pages 49, 50, and 55, "tradesmen" should read "tradespeople."

Elaine Forman Crane January 1992 
A

DEPENDENT

PEOPLE 


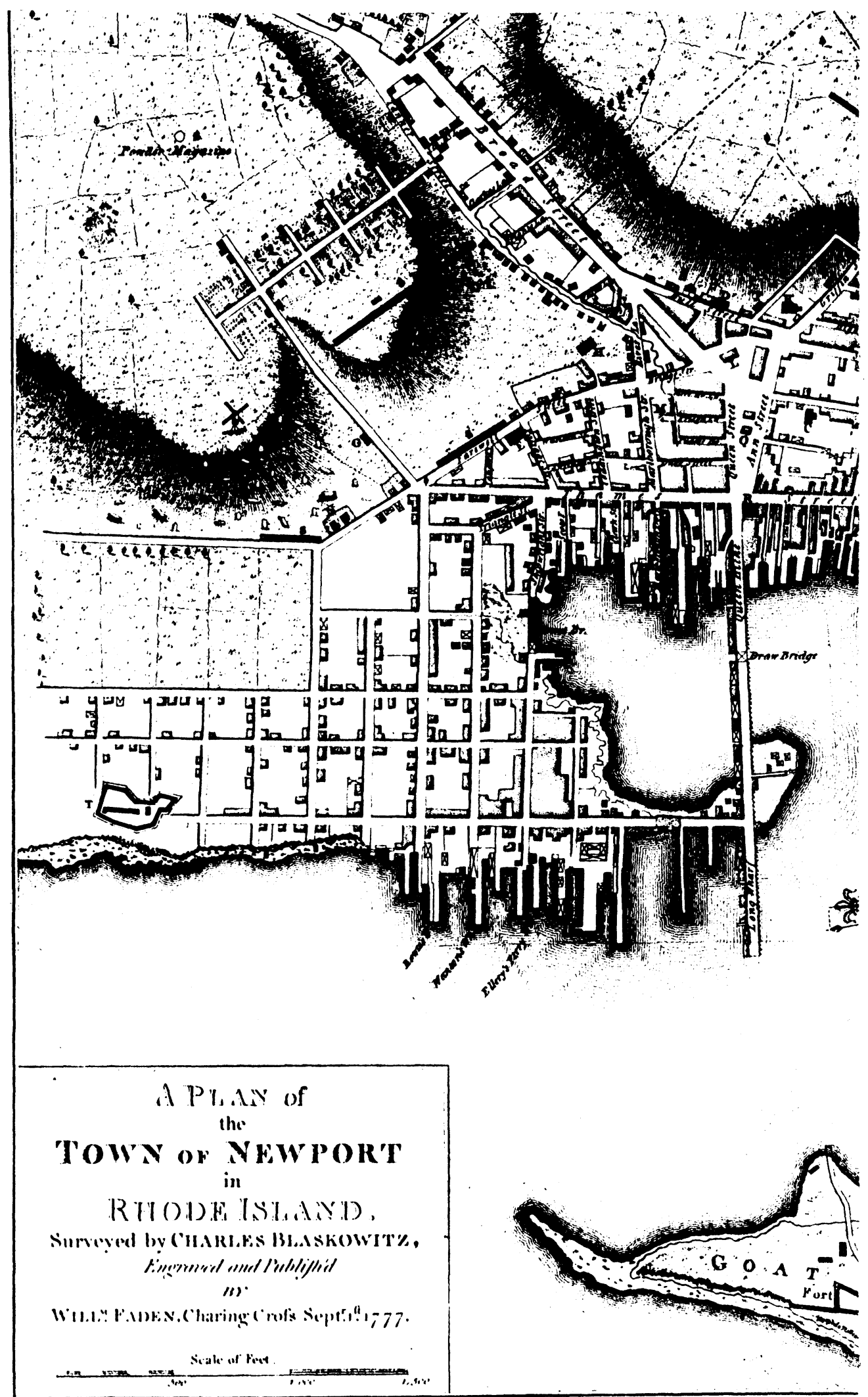




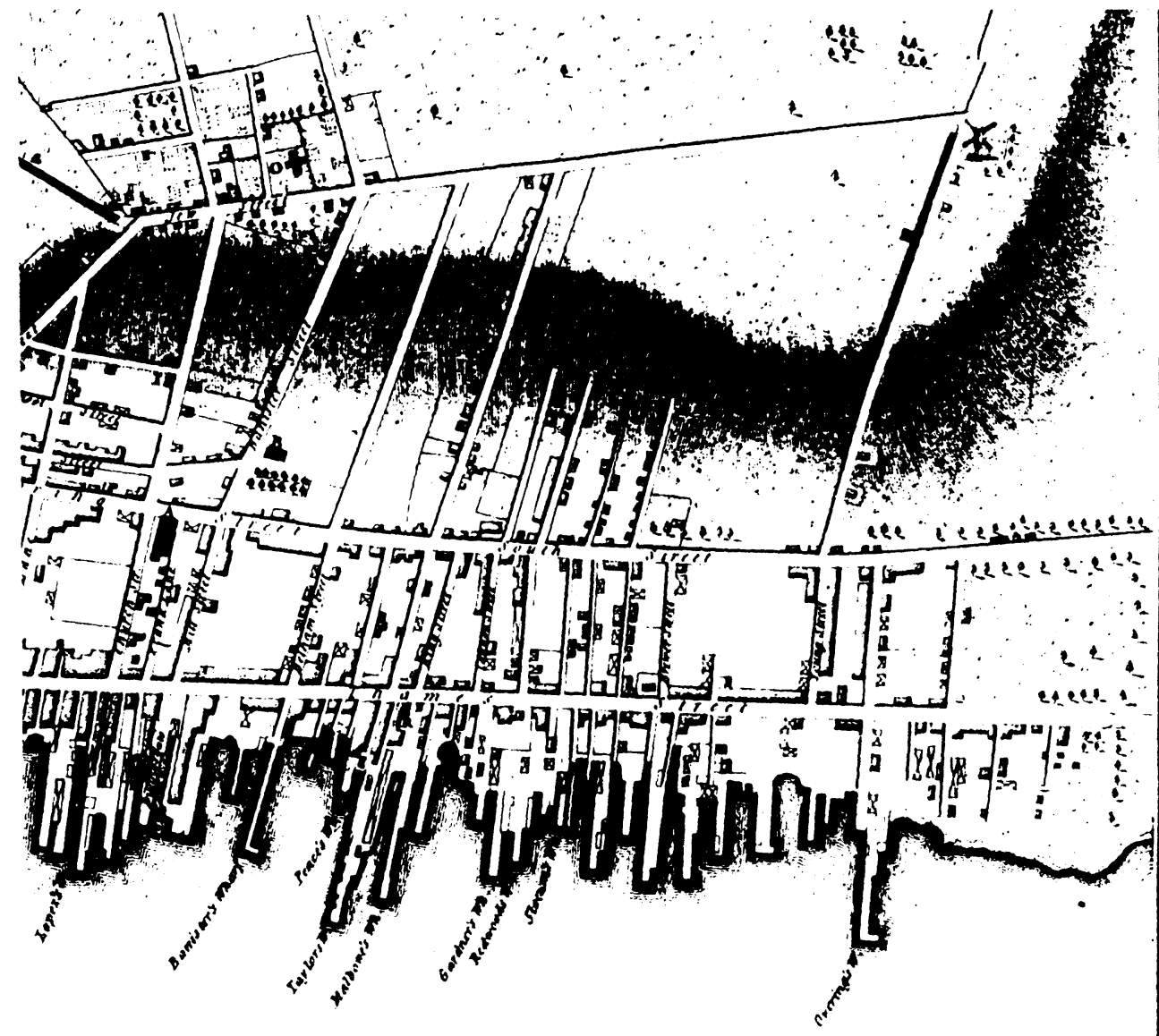

\section{Rederencen}

A Trinise churih .

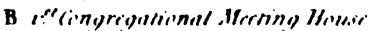

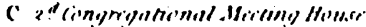

D, "Bupripi Allecring Hewser

E \& Bapriff Herrini) Houser .

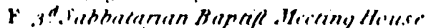

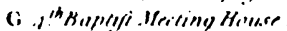

H Finindi, llicrin!) Helew,

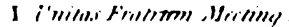

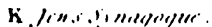

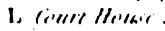

$M$ rimel.

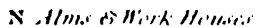

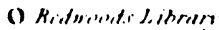

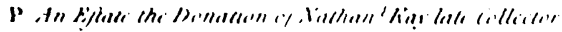
" -

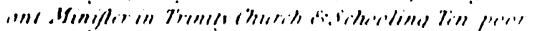
Anen.

Q Jin'n licherel Hinist

R. Markit Hollorior

S Roper Hirlh.

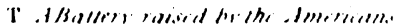




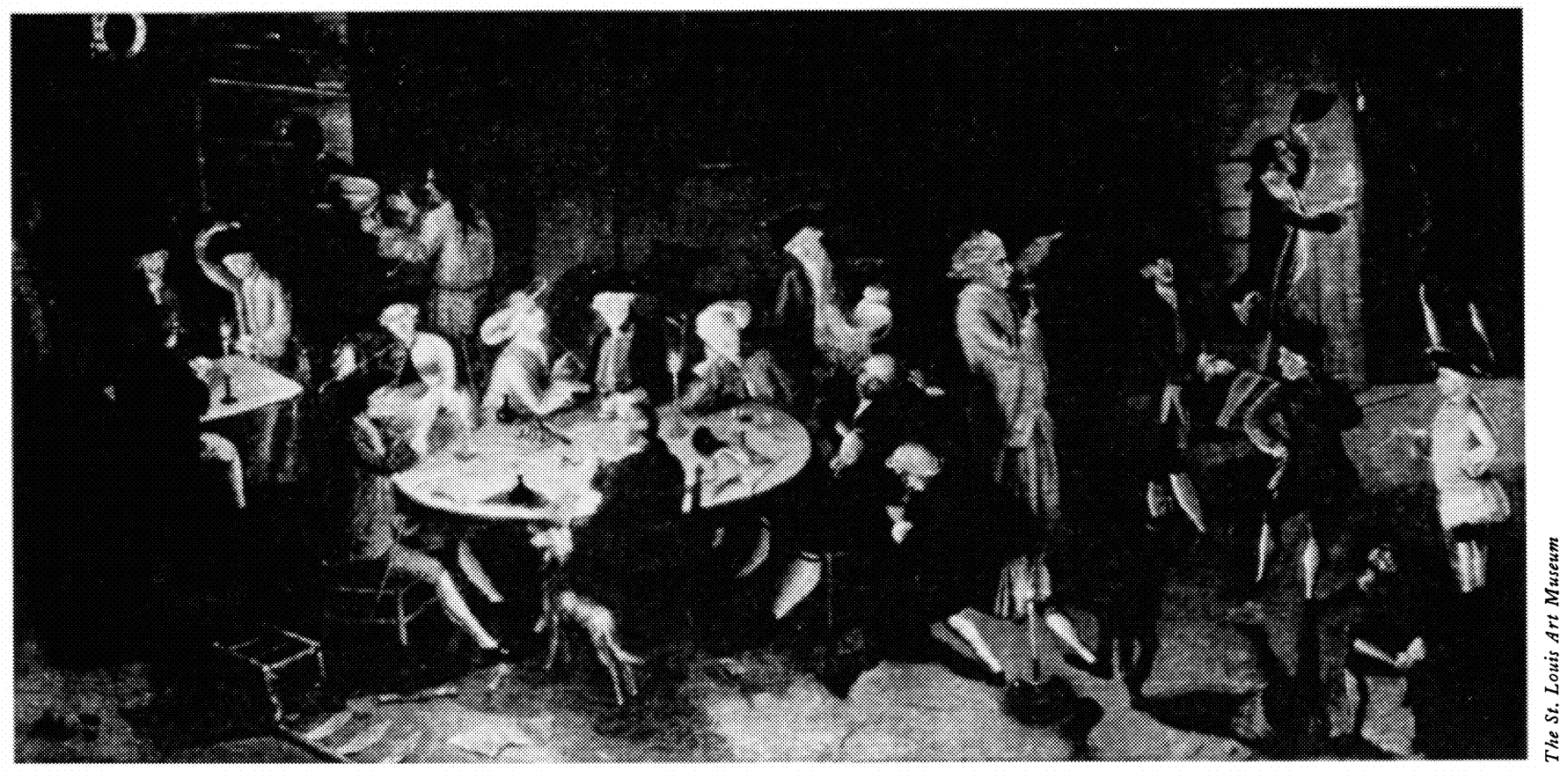

Sea Captains Carousing in Surinam by John Greenwood ca. I 758

Several prominent Rhode Islanders are portrayed in this tavern scene, including Captain Nicholas Cooke, smoking a pipe at the far side of the table and deep in conversation with Captain Esek Hopkins. A second Hopkins-Stephen-spills rum over the sleeping Jonas Wanton, while Ambrose Page vomits into Wanton's pocket, oblivious of the discomfort he will soon feel at his rear. On the right, Nicholas Power appears to be knighting someone who might be Godfrey Malbone, Jr. Behind them, Greenwood has painted himself into the picture, candle in hand, making a hasty retreat. 